\title{
PEMISAHAN LANTHANUM DARI LIMBAH HASIL PENGOLAHAN TIMAH DENGAN MENGGUNAKAN METODE PENGENDAPAN BERTINGKAT
}

\author{
Iwan Hastiawan*, Fajar Firmansyah, Juliandri, Diana Rakhmawaty Eddy, Atiek Rostika Noviyanti \\ Departemen Kimia, Fakultas Matematika dan Ilmu Pengetahuan Alam, Universitas Padjadjaran, Jln. Raya \\ Bandung-Sumedang km. 21 Jatinangor, Sumedang, Jawa Barat, 45363 \\ *Alamat Korespondensi: hastiawan@unpad.ac.id
}

\begin{abstract}
Abstrak: Di Indonesia mineral mengandung unsur tanah jarang terdapat di dalam mineral bawaan pada komoditas utama terutama emas dan timah. Unsur tanah jarang sesuai namanya merupakan unsur yang langka, di alam berupa senyawa kompleks fospat dan karbonat. Lanthanum merupakan unsur dengan nomor atom 57 dan termasuk dalam golongan unsur tanah jarang ringan. Lanthanum oksida digunakan secara ekstensif pada aplikasi lampu karbon, terutama di industri perfilman untuk lampu studio dan proyeksi. Tujuan penelitian ini adalah mengetahui kadar lanthanum oksida yang diperoleh dari hasil pemisahan dengan menggunakan metode pengendapan bertingkat. Langkah pertama adalah destruksi dengan menggunakan natrium hidroksida. Lalu pembentukan tanah jarang klorida dengan penambahan asam klorida. Selanjutnya pengendapan selektif untuk memisahkan tanah jarang hidroksida. Kemudian pemisahan lanthanum dengan cara pengendapan bertingkat menggunakan ammonium hidroksida. Pengendapan dilakukan dalam tingkatan $\mathrm{pH}$ yang berbeda. Lantanum hidroksida dilarutkan dengan asam nitrat untuk kemudian diendapkan dengan penambahan asam oksalat. Selanjutnya dilakukan kalsinasi pada suhu $1000^{\circ} \mathrm{C}$ selama 2 jam untuk pembentukan lanthanum oksida. Lanthanum oksida dianalisis dengan menggunakan SEM-EDX. Hasil karakterisasi SEM-EDX menunjukkan bahwa lanthanum oksida yang diperoleh dengan menggunakan metode pengendapan bertingkat mempunyai kadar sebesar $86,59 \%$. Efisiensi dari metode pengendapan bertingkat dengan menggunakan ammonium hidroksida sebesar $64,57 \%$.
\end{abstract}

Kata kunci: Limbah hasil pengolahan timah, lanthanum oksida, pengendapan bertingkat

\begin{abstract}
In Indonesia minerals containing rare earth elements are associated with the minerals of primary commodities, especially gold and tin. Rare earth elements as stated are very rare element. On the earth the complex found in of phosphate and carbonate. Lanthanum is the element with atomic number of 57 and part of the light rare earth elements. $\mathrm{La}_{2} \mathrm{O}_{3}$ is used extensively in carbon lighting applications, especially in the film industry for studio lighting and projection. The purpose of this study was to determine the level of $\mathrm{La}_{2} \mathrm{O}_{3}$ obtained from separation by using a multistage precipitation method. The first step is destruction of the mineral using $\mathrm{NaOH}$. Then the formation of $\mathrm{RECl}_{3}$ with the addition of $\mathrm{HCl}$. Furthermore, selective precipitation to separate the $\mathrm{RE}(\mathrm{OH}) 3$. Follow of separation of lanthanum by precipitation using $\mathrm{NH} 4 \mathrm{OH}$. Precipitation was carried out in different level of $\mathrm{pH} . \mathrm{La}(\mathrm{OH})_{3}$ was dissolved with nitric acid and then precipitated by addition of oxalic acid. The precipitation was calcinated at a temperature of $1000^{\circ} \mathrm{C}$ for 2 hours for the formation of $\mathrm{La}_{2} \mathrm{O}_{3}$. $\mathrm{La}_{2} \mathrm{O}_{3}$ were analyzed using SEM-EDX. The results of SEM-EDX characterization showed that $\mathrm{La}_{2} \mathrm{O}_{3}$ obtained using multistage precipitation method was $86.59 \%$. Efficiency of the multistage precipitation method using ammonium hydroxide rise by $64.57 \%$.
\end{abstract}

Keywords: tin mining waste, lanthanum oxide, multistage precipitation

\section{PENDAHULUAN}

Unsur tanah jarang (UTJ) di Indonesia tersebar di Pulau Sumatera, Pulau Kalimantan, Pulau Jawa, Pulau Sulawesi dan Pulau Papua. Secara geologi endapan UTJ berasosiasi dengan batuan asam (granitik) dan endapan fosfatik. Dalam lingkungan batuan asam, endapan UTJ dijumpai sebagai mineral ikutan pada penambangan timah plaser seperti monasit dan senotim di Pulau Bangka dan Belitung (Suwargi dkk. 2010).

Dua macam bijih fosfat yang diketahui mengandung unsur tanah jarang adalah monasit dan senotim. Monasit biasanya mengandung lebih banyak kelompok unsur tanah jarang ringan, sedangkan senotim kaya akan logam tanah jarang berat (Johari \& Kuntjara 1991).
Dari perspektif industri, unsur-unsur tanah jarang (skandium, itrium, dan lantanida) sangat penting karena memiliki sifat yang unik dan diaplikasikan di berbagai bidang seperti elektronik, magnetik, metalurgi, phosphors, katalis, kaca, dan keramik teknologi laser. Dengan meningkatnya permintaan kemurnian yang tinggi untuk UTJ dan senyawanya, pemisahan dan pemurnian dari unsur-unsur ini telah mendapatkan perhatian (Yin et al. 2007).

Lanthanum ditemukan pada tahun 1839 oleh Carl Gustav Mosander. Lantanum diisolasi secara murni pertama kali pada tahun 1923. Lanthanum diklasifikasikan ke dalam UTJ dan masuk ke dalam golongan lantanida. Pada umumnya lanthanum berada pada kulit bumi. Kelimpahannya di bumi sangat banyak sekitar 18 bpj (Topp 1965). 
Lanthanum merupakan unsur utama dalam deretan ini dengan nomor atom 57 dan termasuk dalam golongan unsur tanah jarang ringan. Di alam lanthanum terdapat dalam mineral monasit, senotim, serit, alanit, eukolit, melanoserit, samarit, fergusomit, dan lantanit (Supriyanto 1996).

Pada tahun 1986 terjadi sebuah terobosan di bidang superkonduktivitas yaitu ditemukannya suatu keramik yang terdiri dari unsur lanthanum, barium, tembaga, dan oksigen yang bersifat sebagai superkonduktor dengan suhu kritis $30 \mathrm{~K}$ atau dikenal dengan superkonduktor suhu tinggi (Barmawi 2000).

Pemisahan atau pemurnian logam tanah jarang dari uranium dan thorium dapat dilakukan dengan berbagai cara yaitu ekstraksi, resin penukar ion, atau pengendapan (Hafni dkk.1998).

Pengendapan merupakan salah satu metode pemisahan unsur logam tanah jarang yang cukup banyak digunakan. Pengendapan dilakukan dengan mengubah zat yang akan dipisahkan menjadi suatu fasa baru yaitu dalam bentuk padatan (endapan). Pengendapan ini terjadi karena zat tersebut berada dalam bentuk persenyawaan yang hasil kali konsentrasi ion-ionnya melebihi harga hasil kali kelarutan (Ksp) senyawa tersebut (Wasito \& Biyantoro 2009).

Proses pengendapan dapat dipakai untuk peningkatan kadar unsur dan juga untuk pemisahan unsur dengan unsur yang lain. Proses pengendapan merupakan proses pemisahan yang mudah, cepat dan murah (Suyanti dkk. 2008).

Untuk meningkatkan kadar unsur tanah jarang dilakukan dengan menggunakan pengendapan bertingkat. Proses pengendapan merupakan proses pemisahan yang mudah, cepat, dan murah (Prakash 1975).

Pada penelitian ini, akan dilakukan pemisahan lanthanum dari limbah hasil penambangan timah. Metode yang digunakan menggunakan metode pengendapan bertingkat yang diadopsi dari yang telah dilakukan oleh Soe et al. (2008). Metode ini dipilih bertujuan untuk menghasilkan lanthanum dengan kadar yang tinggi. Produk akhir yang dihasilkan berupa lanthanum oksida.

\section{BAHAN DAN METODE}

\section{Alat}

Alat-alat yang dipakai dalam penelitian ini adalah corong buchner, desikator, kertas saring Whatman No.41, mortar, neraca analitis, hot plate dan pengaduk magnet, penganyak 200-mesh, $\mathrm{pH}$ meter, tanur, termometer, oven, ICP-AES, SEM-EDX, dan alat-alat gelas lain yang ada di laboratorium.

\section{Bahan}

Bahan yang digunakan dalam penelitian ini berasal dari limbah hasil penambangan timah. Bahan kimia yang digunakan adalah akuades, ammonium hidroksida, asam klorida $37 \%$, asam nitrat $65 \%$, asam oksalat, kalium permanganat, natrium bikarbonat, dan natrium hidroksida (Merck).

\section{Analisis Mineralogi Sampel}

Sampel berupa pasir monasit. Dilakukan analisis mineralogi dengan menggunakan ICP-AES terhadap pasir monasit tersebut untuk mengetahui kandungan lanthanum yang terdapat dalam sampel tersebut.

\section{Penyiapan sampel}

Pasir digerus dan diayak 200 mesh, kemudian ditimbang sebanyak 10,3051 g dan dimasukkan ke dalam gelas kimia.

\section{Destruksi Sampel dengan Menggunakan Natrium Hidroksida}

Sebanyak $75 \mathrm{~mL}$ natrium hidroksida 10,2 M ditambahkan ke dalam gelas kimia yang berisi sampel. Selanjutnya sampel dipanaskan pada suhu $140^{\circ} \mathrm{C}$ disertai dengan pengadukan selama 2 jam. Suhu dikontrol dengan penambahan akuades. Setelah destruksi selama 2 jam, campuran ditambahkan akuades hingga suhunya mencapai $105^{\circ} \mathrm{C}$ selama 1 jam. Suhu dikontrol dengan sedikit penambahan akuades. Campuran disaring dan endapan yang menyerupai lumpur dibilas dengan air panas. Kemudian endapan dikeringkan dalam oven pada suhu $100^{\circ} \mathrm{C}$ selama 1 jam.

\section{Pembentukan $\mathrm{RECl}_{3}$}

Endapan ditambahkan asam klorida $37 \%$ sebanyak $50 \mathrm{~mL}$, kemudian campuran dipanaskan pada suhu $80^{\circ} \mathrm{C}$ selam 1 jam. Setelah itu dilakukan pengenceran dengan penambahan air panas. Campuran disaring dengan menggunakan corong Buchner. Filtrat hasil penyaringan dipisahkan ke dalam gelas kimia sedangkan endapan dibuang.

\section{Pengendapan Selektif}

Filtrat dimasukkan ke dalam gelas kimia dan diendapkan dengan penambahan ammonium hidroksida hingga mencapai $\mathrm{pH}$ 5,8. Setelah itu dilakukan penyaringan. Filtrat yang diperoleh dipisahkan untuk diendapkan kembali. Pengendapan dilakukan dengan penambahan ammonium hidroksida hingga mencapai $\mathrm{pH}$ 11. Campuran disaring dan endapan yang diperoleh dipisahkan (Soe et al. 2008).

\section{Pemisahan Lanthanum Dengan Menggunakan Metode Pengendapan Bertingkat}

Endapan ditambahkan asam nitrat $65 \%$ dan dipanaskan pada suhu $90^{\circ} \mathrm{C}$. Kemudian ditambahkan kalium permanganat $0,5 \mathrm{M}$ dan dipanaskan selama 1 jam pada suhu $40^{\circ} \mathrm{C}$. Setelah itu campuran diendapkan dengan natrium karbonat 2,45 M pada pH 3,95. Endapan disaring untuk diambil filtratnya. Filtrat yang diperoleh diendapkan dengan asam oksalat 0,5 M. Endapan disaring, kemudian endapan yang diperoleh dikalsinasi dalam tanur pada suhu 
$1000^{\circ} \mathrm{C}$ selama 2 jam. Setelah itu, tanah jarang oksida ditambahkan asam nitrat $65 \%$ sambil dipanaskan pada suhu $90^{\circ} \mathrm{C}$ selama 1 jam. Selanjutnya diendapkan dengan ammonium hidroksida hingga mencapai $\mathrm{pH}$ 7,6. Endapan disaring, filtrat yang diperoleh diendapkan dengan ammonium hidroksida hingga mencapai $\mathrm{pH}$ 9,6. Endapan disaring, kemudian ditambahkan asam nitrat $65 \%$ sambil dipanaskan pada suhu $90^{\circ} \mathrm{C}$ selama 1 jam. Campuran ditambahkan asam oksalat 0,5 M hingga terbentuk endapan. Endapan yang masih berada di dalam larutan induk dipanaskan di dalam penangas air. Kemudian dipindahkan ke cawan porselen dan dikalsinasi pada suhu $1000^{\circ} \mathrm{C}$ selama 2 jam (Soe et al. 2008).

\section{Karakterisasi Dengan Menggunakan SEM-EDX}

Endapan yang diperoleh ditimbang, kemudian dilakukan karakterisasi dengan SEM-EDX untuk mengetahui kadar lanthanum oksida yang diperoleh.

\section{HASIL DAN PEMBAHASAN}

Sampel dianalisis dengan menggunakan ICP-AES untuk mengetahui kandungan lanthanum dari monasit tersebut. Hasil analisis dapat dilihat pada Tabel 1. Dari hasil analisis dapat diketahui bahwa kandungan lanthanum dalam sampel sebesar 2,98\%.

Lanthanum oksida yang diperoleh dianalisis dengan menggunakan SEM-EDX. SEM-EDX dapat memberikan informasi mengenai morfologi dan komposisi dari hasil yang didapat.

Tabel 1. Hasil analisis mineralogi dari sampel dengan menggunakan ICP-AES

\begin{tabular}{lcc}
\hline No & Unsur & \% Berat \\
\hline 1. & Lanthanum & 2,98 \\
2. & Gadolinium & 0,50 \\
\hline
\end{tabular}

Pada Gambar 1 menunjukkan morfologi dari hasil yang didapat dengan perbesaran $1000 \times$. Berdasarkan hasil foto dengan perbesaran $1000 \times$, dapat terlihat bahwa partikel berbentuk granul karena merupakan ripening pada saat nukleisasi dan pertumbuhan partikel. Ukuran dari partikel juga tidak homogen dan tingkat pengelompokan/aglomerasi yang tinggi. Aglomerasi mengakibatkan distribusi partikel menjadi tidak homogen dan dapat menyebabkan pengotor-pengotor masuk ke kisi-kisi oksida yang tidak homogen sehingga pada saat pengukuran akan terdeteksi.

Analisis dengan menggunakan SEM-EDX juga memberikan informasi mengenai komposisi (Tabel 2). Informasi tentang komposisi ini berasal melalui energi yang dihasilkan oleh sinar-X. Pada spektrum yang dihasilkan oleh EDX, sumbu $\mathrm{X}$ menunjukkan energi sinar-X yang dihasilkan oleh setiap atom dalam satuan keV, sedangkan sumbu Y menunjukkan intensitas sinar yang terserap sebanding dengan persen (\%) massa pada unsur yang terdapat pada sampel. Secara analisis kualitatif metode EDX ini memberikan informasi jenis unsur yang terkandung dalam bahan. Gambar 2 menunjukkan hasil EDX dari lanthanum oksida yang diperoleh.

Tabel 2. Komposisi hasil pemisahan lanthanum yang diukur dengan menggunakan SEM-EDX

\begin{tabular}{cccc}
\hline Senyawa & keV & $\begin{array}{c}\text { Massa } \\
(\%)\end{array}$ & $\begin{array}{c}\text { Galat } \\
(\%)\end{array}$ \\
\hline $\mathrm{CuO}$ & 8,040 & 4,02 & 1,78 \\
$\mathrm{ZnO}$ & 8,630 & 2,60 & 2,23 \\
$\mathrm{La}_{2} \mathrm{O}_{3}$ & 4,648 & 86,59 & 1,27 \\
\hline
\end{tabular}

Perbedaan energi sinar-X pada setiap unsur ini disebabkan karena perbedaan kemampuan setiap unsur untuk memindahkan elektron bagian luar ke dalam kulit yang telah ditinggalkan akibat penembakan oleh sinar-X. Unsur-unsur lantanida mempunyai konfigurasi elektron yang sama (elektron terluar menempati sub kulit orbital $6 s^{2}$, sedangkan kedudukan elektron yang berbeda pada orbital $\mathrm{M}$ (sub kulit orbital $4 f$ ). Oleh sebab itu energi kuantum elektron pada kulit $\mathrm{K}$ dari unsur lantanida hampir sama, hal ini akan menyebabkan terjadinya interferensi antar sinar-X karakteristik hasil transisi elektron ke orbital ini. Sedang nilai energi kuantum

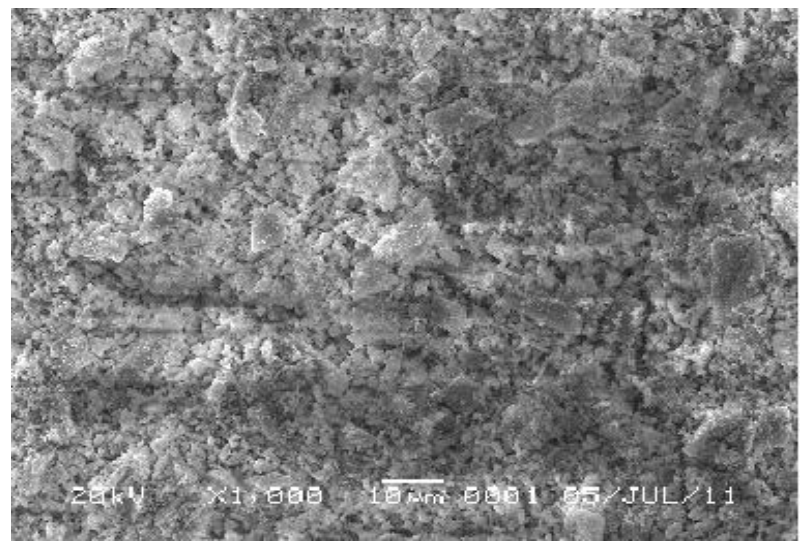

Gambar 1. Hasil foto SEM dengan perbesaran $1000 \times$ pada lanthanum oksida 


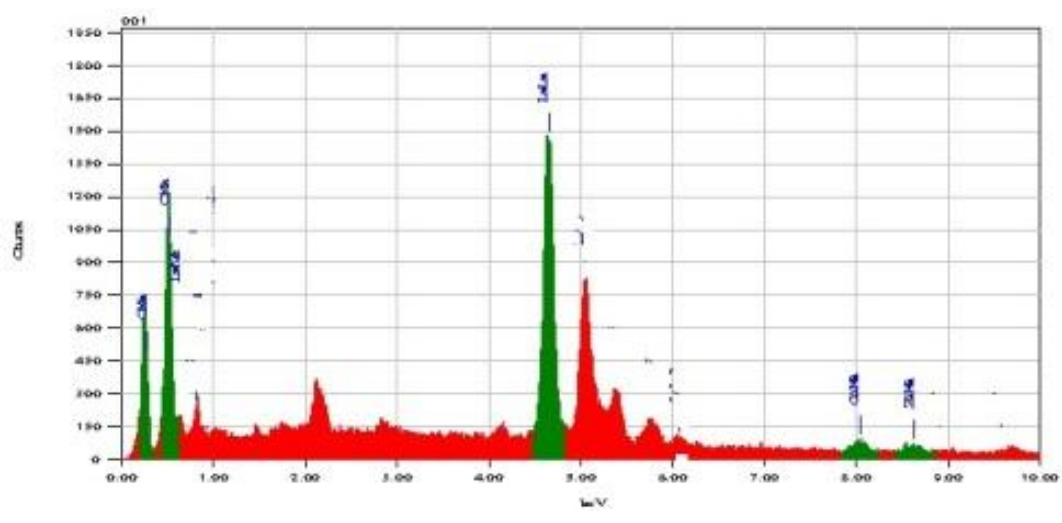

Gambar 2. Spektrum EDX dari lanthanum oksida

elektron pada orbital L dan M berbeda untuk setiap unsur, sehingga kemungkinan analisis unsur lantanida terutama unsur tanah jarang dapat dilakukan dengan menganalisis spektrum sinar-X karakteristik hasil transisi elektron ke kulit L dan K. Kulit L lebih sering dipilih untuk menganalisis spektrum sinar-X karakteristik karena pada kulit L pada daerah energi antara 4,40 keV sampai 7,50 keV, kebolehjadian pembentukan sinar-X berada diantara kedua trasisi (lebih kecil dari 0,125) dan tampang lintang pembentukan sinar-X lebih kecil dari 479 barn, maka puncak spektrum karakteristik unsur ini berada dalam daerah analisis. Sedangkan pada kulit $\mathrm{K}$ meskipun energi ikat elektron dan kebolehjadinnya lebih tinggi tetapi tampang lintang pembentukan sinar-X yang dimiliki sangat kecil (lebih kecil dari $6,3 \times 10^{-2}$ barn), sehingga puncak spektrum fluoresensi sinar-X hasil transisi ini sangat lemah dan berada di luar jangkauan daerah energi analisis (Nampira dkk. 2001).

Hasil spektrum EDX menunjukkan bahwa lanthanum terletak pada 4,648 keV. Selain itu terdapat beberapa pengotor seperti $\mathrm{CuO}$ yang terletak pada $8,040 \mathrm{keV}$ dan $\mathrm{ZnO}$ pada 8,630 keV. Adanya pengotor - pengotor tersebut dikarenakan pada saat melakukan penelitian dilakukan di ruangan terbuka. Hasil spektrum juga menunjukkan bahwa kadar lanthanum oksida sebesar $86,59 \%$.

\section{KESIMPULAN}

Hasil analisis dengan menggunakan SEM-EDX menunjukkan bahwa kadar lanthanum oksida yang diperoleh sebesar 86,59\%. Efisiensi dari metode pengendapan bertingkat dengan menggunakan ammonium hidroksida sebesar $64,57 \%$.

\section{DAFTAR PUSTAKA}

Barmawi. (2000). Superkonduktor Suhu Tinggi. Kompas.

Hafni, L.N., Faizal, R., Sugeng, W., Budi, S., Arif, S. \& Susilaningtyas. (1998). Pengolahan Monasit dari Limbah Penambangan Timah: Pemisahan Logam Tanah Jarang (RE) dari $U$ dan Th. Prosiding Presentasi Ilmiah Daur Bahan Bakar Nuklir V. Jakarta, 22 Pebruari 2000. Hal. 54-60.
Johari \& Kuntjara. (1991). The Occurences of Rare Earth Mineral for Electronic Uses. Prince of Songkala University. Thailand

Nampira, Y., Amini, S. \& Kriswarini, R. (2001). Analisis unsur lantanida dalam mineral monasit secara fluoresensi sinar-X. Prosiding Presentasi Ilmiah Daur Bahan Bakar Nuklir VI. Jakarta, 7-8 Nopember 2001. Hal. 191-196.

Prakash, S. (1975). Advanced Chemistry of Rare earth Elements. S.Chamc \& Co. Raam Nagar. New Delhi.

Soe, N. N., Shwe, L.T. \& Lwin, K.T. (2008). Study on extraction of lanthanum oxide from monazite concentrate. World Academy of Science, Engineering and Technology. 46: 142145.

Supriyanto, R. (1996). Ekstraksi Lanthanum (III) dengan Teknik Membran Cair Berpendukung. Tesis. Bandung: Institut Teknologi Bandung.

Suwargi, E., Pardiarto, B. \& Ishlah, T. (2010). Potensi logam tanah jarang di Indonesia. Buletin Sumber Daya Geologi. 5(3): 131-140.

Suyanti, Purwani M.V. \& Muhadi, A.W. (2008). Peningkatan Kadar Neodimium Secara Proses Pengendapan Bertingkat Memakai Amonia. Seminar Nasional IV SDM Teknologi Nuklir. Yogyakarta, 25-26 Agustus 2008. Hal. 430-438.

Topp, N.E. (1965). The Chemistry of The Rare Earth Elements. New York: Elsevier Publishing Company.

Wasito, B. \& Biyantoro, D. (2009). Optimasi proses pembuatan oksida logam tanah jarang dari pasir Senotim dan analisis produk dengan Spektrometer Pendar Sinar-X. Seminar Nasional V SDM Teknologi Nuklir. Yogyakarta, 5 Nopember 2009. Hal. 677-686.

Yin, J., Hu, B., He, M. \& Jiang, Z.C. (2007). Determination of trace rare earth elements in environmental samples by low temperature electrothermal vaporization inductively coupled plasma mass spectrometry after synergistic extraction with dimethylheptyl methyl phosphate and 1-phenyl-3-methyl-4benzoylpyrazalone-5. Analytica Chimica Acta. 594(1): 61-68. 